\title{
Interleukin-36 in Infectious and Inflammatory Skin Diseases
}

\author{
Anna-Lena Buhl and Joerg Wenzel* \\ Department of Dermatology and Allergy, University Hospital of Bonn, Bonn, Germany
}

Interleukin-36 (IL-36) comprises to a cytokine family consisting of four isoforms IL-36 $\alpha$, IL-36 $\beta$, IL-36 $\gamma$, and IL-36 receptor antagonist (IL-36 Ra). These IL-36 cytokines, in turn, belong to the IL-1 superfamily. The IL-36 receptor (IL-1R6) is functional as a heterodimer formed of IL-1R6 and IL-1 receptor accessory protein (IL-1RAcP). IL-36 $\alpha, I L-36 \beta$, and IL-36 $\gamma$ are regarded as pro-inflammatory ligands and IL-36 Ra as well as IL-38 as anti-inflammatory ligands of IL-1R6. IL-36 cytokines are mainly expressed on the barrier sites of the body e.g., bronchial, intestinal, and dermal epithelium. One of their most important biological functions is the bridging of innate and adaptive immune responses. A disturbed balance between pro-inflammatory and anti-inflammatory branches easily leads to inflammation of the corresponding tissue. The most prominent example for an altered IL-36 expression is the spectrum of psoriasis. In addition to inflammatory

OPEN ACCESS

Edited by:

Ralf J. Ludwig,

Universität zu Lübeck, Germany

Reviewed by:

Heiko Mühl,

Goethe-Universität Frankfurt am

Main, Germany

Unni Samavedam,

University of Cincinnati, United States

*Correspondence:

Joerg Wenzel

joerg.wenze/@ukbonn.de

Specialty section:

This article was submitted to

Autoimmune and Autoinflammatory

Disorders,

a section of the journal

Frontiers in Immunology

Received: 03 April 2019

Accepted: 08 May 2019

Published: 24 May 2019

Citation:

Buhl A-L and Wenzel J (2019)

Interleukin-36 in Infectious and

Inflammatory Skin Diseases.

Front. Immunol. 10:1162.

doi: 10.3389/fimmu.2019.01162 dermatoses, IL-36 also seems to play a role in infectious dermatoses. Microbial triggers, especially Staphylococcus aureus infection, increase the production of pro-inflammatory IL-36 cytokines and initiate/promote the inflammation of skin lesions. Due to the discovery of IL-36 as an important immune mediator, it has already been possible to develop important diagnostic tools for dermatitis. Not only in the field of inflammatory skin diseases, but also in pulmonary and intestinal inflammation, there is evidence that IL-36 cytokines might have diagnostic and/or therapeutic relevance.

Keywords: IL-36, IL-36y, inflammation, infection, skin, dermatosis, psoriasis

\section{INTRODUCTION}

Interleukin-36 (IL-36) is a member of the IL-1 superfamily discovered about 20 years ago (1-3). The four existing isoforms have been renamed several times (4). They were formerly known as IL-1F6, IL-1F8, IL-1F9, and IL-1F5. Since their functions were revealed about one decade ago, they were finally assigned as IL-36 $\alpha$, IL-36 $\beta$, IL-36 $\gamma$, and IL-36 receptor antagonist (Ra) $(4,5)$. While

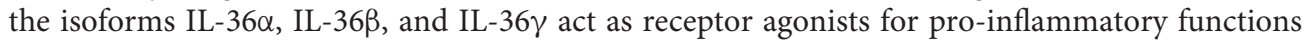
(6), IL-36 Ra acts as an anti-inflammatory mediator (7). All IL-36 cytokines are encoded closely to each other on the human chromosome 2 within a cluster containing most of the remaining IL-1 cytokines (8-10). IL-36 cytokines are increasingly associated with inflammatory diseases. Among the associated diseases are Inflammatory Bowel Disease (IBD) $(11,12)$, rheumatoid and psoriatic arthritis (13), and various inflammatory and infectious skin disorders (14). Among the IL-36 associated skin diseases, psoriasis is the most prominent one (15-17), in which IL-36 $\gamma$ was identified as a specific biomarker (18). This review summarizes the current state of knowledge about IL-36, focusing on the special role of IL-36 in the dermatopathological context, and provides insights into the possibilities of using IL-36 as a potent pharmaceutical target in dermatology. 


\section{EXPRESSION, INDUCTION, AND REGULATION OF IL-36}

The expression of IL-36 cytokines and IL-36 receptor (IL-1R6) has been described in many different tissues (Table 1). The underlying expression profile is more limited compared to that of the "traditional" IL-1 cytokines (19). IL-1R6 is mainly found on epithelial cells at the barrier sites of an organism $(6,15)$. The IL-36 isoforms IL-36 $\alpha$, IL-36 $\beta$, IL-36 $\gamma$, and IL-36 receptor antagonist (IL-36 Ra) are predominantly produced in the skin by keratinocytes (20). Furthermore, the isoforms IL-36 $\alpha$ and IL-36 $\gamma$ are expressed in the respiratory tract (21) and IL-36 3 as

\begin{tabular}{|c|c|c|c|c|c|c|}
\hline IL-36 $\alpha$ & IL-1F6 & $\begin{array}{l}\text { Skin } \\
\text { Respiratory tract } \\
\text { Bone-marrow } \\
\text { Tonsils } \\
\text { Lymph nodes } \\
\text { Spleen } \\
\text { Intestines } \\
\text { Synovium (inflamed) } \\
\text { Keratinocytes } \\
\text { B-Lymphocytes } \\
\text { Plasma cells } \\
\text { T-Lymphocytes } \\
\text { Dendritic cells } \\
\text { Monocytes }\end{array}$ & $\begin{array}{l}\text { Neutrophil derived } \\
\text { proteases: } \\
\text { Cathepsin G } \\
\text { Elastase }\end{array}$ & $\begin{array}{l}\text { IL1R6 with recruitment } \\
\text { of IL-1RAcP }\end{array}$ & Pro-inflammatory & $\begin{array}{l}(2,5-7,11-13,16,19- \\
27)\end{array}$ \\
\hline 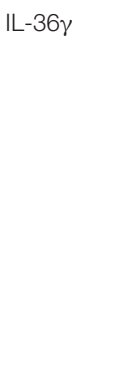 & IL-1F9 & $\begin{array}{l}\text { Skin } \\
\text { Respiratory tract } \\
\text { Intestines } \\
\text { Brain } \\
\text { Synovium (inflamed) } \\
\text { Keratinocytes } \\
\text { B-Lymphocytes } \\
\text { Plasma cells } \\
\text { T-Lymphocytes } \\
\text { Dendritic cells } \\
\text { Monocytes }\end{array}$ & $\begin{array}{l}\text { Neutrophil derived } \\
\text { proteases: } \\
\text { Proteinase-3 } \\
\text { Elastase }\end{array}$ & $\begin{array}{l}\text { IL1R6 with recruitment } \\
\text { of IL-1RAcP }\end{array}$ & Pro-inflammatory & $\begin{array}{l}(3,5-7,11,12,16,19- \\
23,25-28,30,31)\end{array}$ \\
\hline IL-36Ra & IL-1F5 & $\begin{array}{l}\text { Skin } \\
\text { Spleen } \\
\text { Brain } \\
\text { Heart } \\
\text { Kidney } \\
\text { Uterus } \\
\text { Placenta } \\
\text { Synovium (inflamed) } \\
\text { Keratinocytes } \\
\text { B-Lymphocytes } \\
\text { Dendritic cells } \\
\text { Monocytes } \\
\text { Macrophages }\end{array}$ & $\begin{array}{l}\text { Neutrophil derived } \\
\text { protease: } \\
\text { Elastase }\end{array}$ & $\begin{array}{l}\text { IL1R6 w/o recruitment } \\
\text { of IL-1RAcP }\end{array}$ & Anti-inflammatory & $\begin{array}{l}(1-3,5-7,9,19,21 \\
25,30,32)\end{array}$ \\
\hline
\end{tabular}


well as IL-36 $\gamma$ are expressed in the intestines (28). The presence

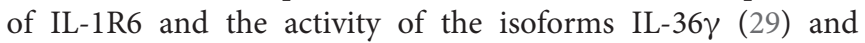
IL-36 Ra (30) was shown in murine glial cells, suggesting a role of IL-36 axis in brain physiology. It is also known that immune cells such as plasma cells, T-cells, macrophages and dendritic cells (DC) produce IL-36 under certain conditions $(2,20,22)$, such as inflammation due to pathological changes. The expression of IL-36 cytokines and their regulation in the skin is well-studied. Some reports suggest a role of epidermal growth factor (EGF) in the regulation of IL-36 $\alpha$ and IL-36 $\beta$ in the skin $(23,24)$. Furthermore, the transcription factor T-bet was found to regulate IL-36y in myeloid cells (33). Takaishi et al. treated the skin of mice with imiquimod. Compared to wild type mice, there was a stronger, no self-limiting skin inflammation in immunoregulator Regnase 1 (Reg-1) knockout mice with higher IL-36 $\alpha$ levels (34). This uncontrolled inflammation was attenuated in mice carrying a double knockout of Reg-1 and IL-1R6, suggesting a "brake"-like, regulatory function of Reg1 in the IL-36/-IL1R6 signaling (34). Additionally, IL-36 Ra regulates IL-36 cytokine expression (Figure 1). It inhibits the pro-inflammatory cascade in an antagonistic pattern at the IL-1R6. The inhibitory IL-36 Ra was found to be upregulated in keratinocytes after stimulation with exogenous recombinant

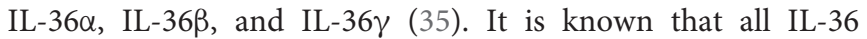
cytokines are produced and secreted in an inactive form without a caspase cleavage site. In contrast to the "traditional" IL-1 cytokines, IL-36 cytokines are regulated independently of the inflammasome (25). The production of IL-36 is induced by many triggers. Carrier et al. demonstrated the induction of IL36 in keratinocytes by TNF, IL-17, IL-22, and IL-36 itself (16). This, in addition to the findings of Swindell et al. allows the assumption that IL-36 appears to be regulated by an autocrine feedback loop (Figure 1). In a monocytic cell line (THP-1) it was shown that the TLR2 and TLR4 ligands Porphyromonas gingivalis lipopolysaccharide (LPS) and Escherichia coli LPS led to an increased IL-36 $\gamma$ induction, but IL-36 $\alpha$ and IL$36 \beta$ were not altered (36). Furthermore, IL-36 $\gamma$ expression in normal human bronchial epithelial cells is increased after stimulation with the TLR3 ligand IL-17A (37). The induction of IL-36 expression by microbial stimuli together with the fact of predominant expression at barrier-sites (predominantly the skin), the IL-36 cytokine family is supposed to play an important role in terms of maintaining homeostasis and first-line defense mechanisms.

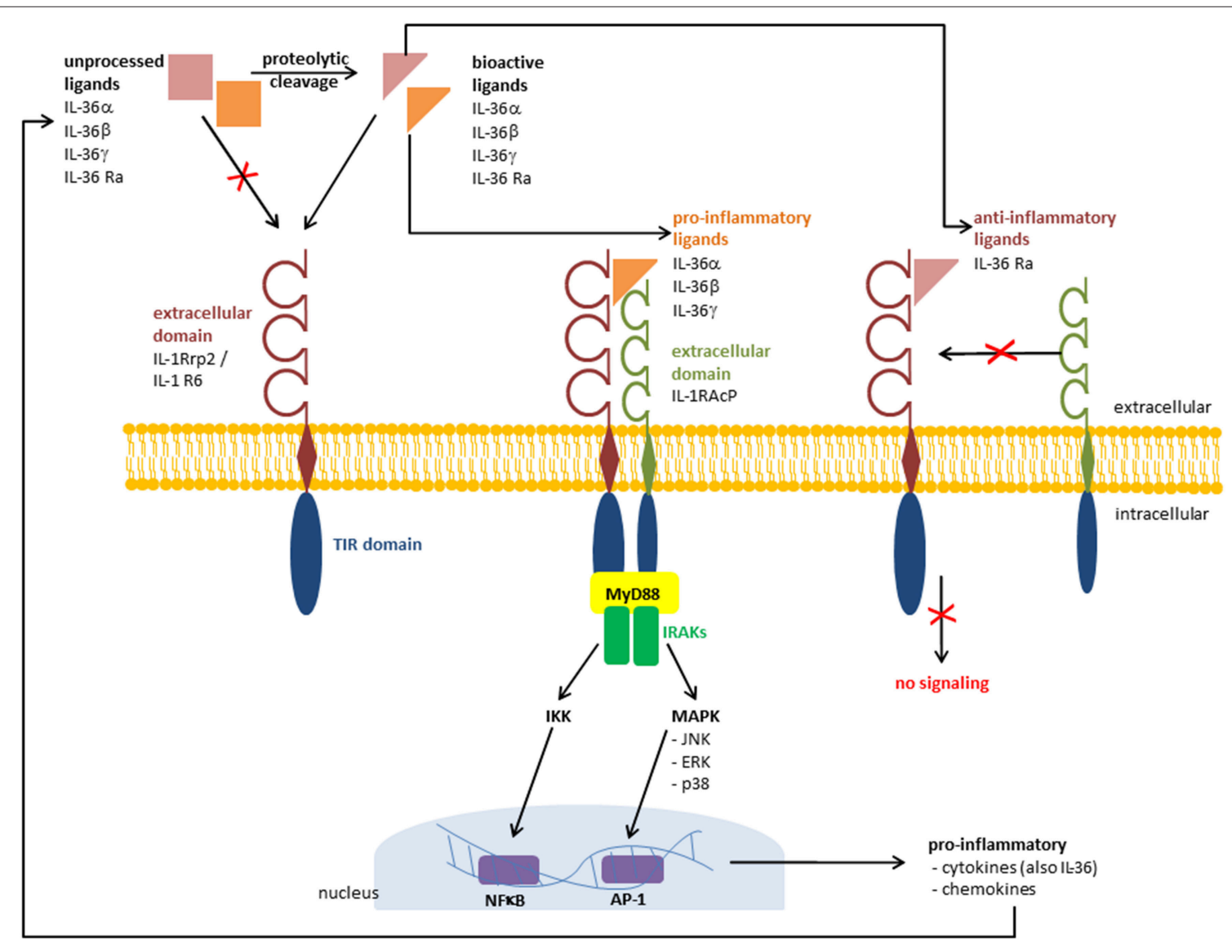

FIGURE 1 | Receptor signaling pathway and recruitment of IL-1RAcP. Pathways that are activated by IL-36 cytokines via IL-36 receptor (IL 1 Rrp2 /IL results in the $\gamma$, and IL $36 \beta, I L$ 36 1 R6). TThe binding of IL-36 activation of pro-inflammatory mediators. The binding of the anti-inflammatory ligand IL 36 Ra prevents the recruitment of IL 1 receptor accessory protein (IL-1RAcP) and the pro-inflammatory cascade is absent. TIR, Toll/Interleukin 1 receptor; MyD88, myeloid differentiation primary response 88; IRAKs, interleukin-1 receptor-associated kinases; NFB, nuclear factor "kappa-light-chain-enhancer" of activated B-cells; AP 1, activator protein 1. 


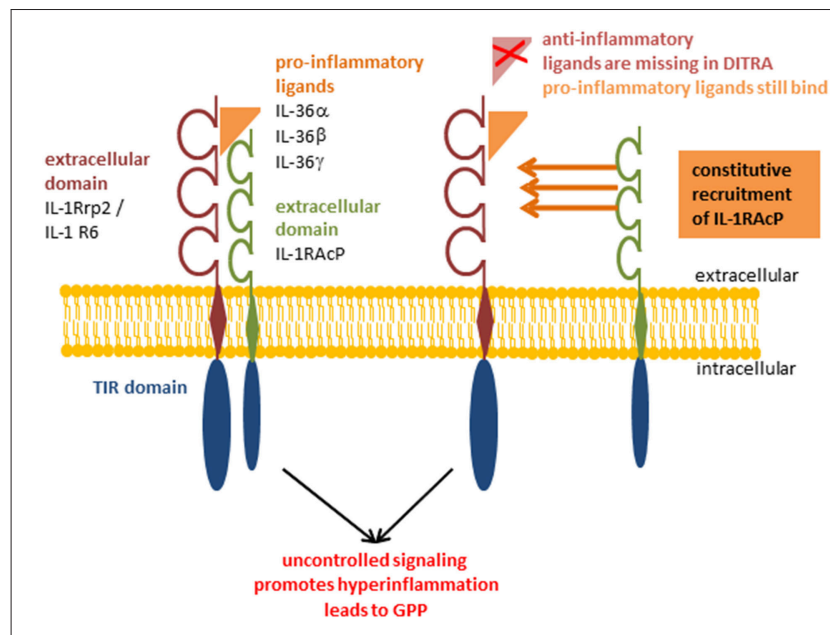

FIGURE 2 | Deficiency of IL-36 Ra (DITRA). Pro-inflammatory IL-36 $\alpha$, IL-36 $\beta$, and IL-36 $\gamma$ bind constitutively to the receptor inducing the signaling cascade without being regulated by anti-inflammatory IL-36 Receptor antagonist. Deficiency of IL-36 Ra (DITRA); generalized pustular psoriasis (GPP).

\section{RECEPTOR AND SIGNALING PATHWAY OF IL-36}

The IL-36 receptor, also known as Interleukin-1 ReceptorRelated Protein 2 (IL-1Rrp2) or Interleukin 1 Receptor Like 2 (IL1RL2) was finally assigned as IL-1R6 (38). Its ligands include all members of the IL-36 family: IL-36 $\alpha$, IL-36 $\beta$, IL$36 \gamma$, and IL-36 Ra. Additionally, IL-38 is known to bind this receptor (39). The highest expression levels of IL-1 R6 can be found in skin and in mammary and mucosal epithelial cell lines $(6,7)$. The signaling pathway of IL-36 receptor agonists

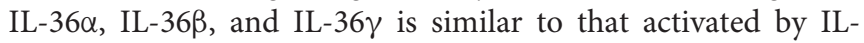
$1 \alpha$ and IL-1 $\beta$ at the IL-1 receptor (7). The recruitment of IL-1 receptor accessory protein (IL-1RAcP) as a co-receptor induces the activation of nuclear factor $-\kappa \mathrm{B}(\mathrm{NF} \kappa \mathrm{B})$ and activation of mitogen-activated protein kinases (MAPK) leading to the induction of pro-inflammatory cytokines, including (IL-12, IL6, TNF $\alpha$, and IL-23) (7, 25). Swindell et al. identified in IL-36 $\gamma$-treated keratinocytes a large number of differentially regulated genes, including IL-1 $\beta$, IL-36 $\gamma$, and the NFKB-target genes TNFAIP3, NFKBIA, NFKB2, CXCL8, and BIRC3 (35). Interestingly, after silencing myeloid differentiation primary response gene 88 (MyD88) via CRISPS/Cas9, the IL-36 $\gamma$ induced alteration of gene expression was missing. This indicates that

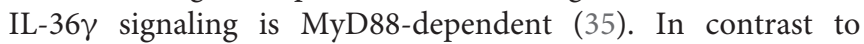
the pro-inflammatory receptor ligands IL-36 $\alpha$, IL-36 $\beta$, and IL$36 \gamma$, binding of IL-36 Ra to IL-1R6 does not lead to the recruitment of IL-1RAcP $(7,25)$. Thus, the pro-inflammatory cascade is not switched on and the anti-inflammatory character of IL-36 Ra is achieved (Figure 1). IL-38 also binds to IL1R6, and has similar anti-inflammatory effects to IL-36 Ra (39). However, it is not an IL-36 family member, but it also belongs to the IL-1 super family. van de Veerdonk et al. found that IL-36 Ra and IL-38 have nearly the same effects on immune cells. Both cytokines IL-36 Ra and IL38 reduce the Candida-induced production of IL-17 and IL2 (39). These findings indicate that not only IL-36 Ra but also IL-38 is a potent natural inhibitor of pro-inflammatory IL-36 cytokines.

\section{PROCESSING AND SECRETION OF IL-36}

Comparable to IL-1 $\alpha$, IL-1 $\beta$, and IL-18, all IL-36 cytokines, including IL-36 $\mathrm{Ra}$ are secreted in an inactive form. They are activated by different proteases upon $\mathrm{N}$-terminal cleavage (25). Due to this cleavage there is an 500-fold increase in activity (26). The responsible proteases have been discovered already. The neutrophil-derived proteases cathepsin $G$ and elastase activate IL-36 $\alpha$, cathepsin G activates IL-36 $\beta$, whereas IL-36 $\gamma$ is activated by the proteases elastase and proteinase- 3 (26). The proteases are able to process IL-36 either as free proteases, or as NET-bound proteases (40). In contrast to the IL-1 receptor antagonist, the antagonistic isoform of IL-36 also requires cleavage at the $\mathrm{N}$-terminus for activation, which is performed by neutrophil elastase (32). It is known that IL-36 $\alpha$, IL-36 $\beta$, and IL-36 $\gamma$ do not have a signal sequence or a caspase cleavage site, so they are assumed to be secreted by an alternative mechanism $(2,3,25)$. However, regarding the secretion mechanism of IL-36, little is known so far. First studies in IL-36 $\alpha$ overexpressing bone marrow-derived macrophages showed that IL-36 $\alpha$ accumulates intracellularly and its secretion depends on LPS/ATP stimulus (41). Similarly, Lian et al. showed that stimulation of human keratinocytes with flagellin alone led to intracellular accumulation of

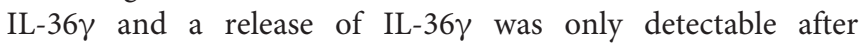
stimulation with the RNA-analog polyinosinic-polycytidylic acid poly(I:C) (42). Based on these findings, Kovach et al.

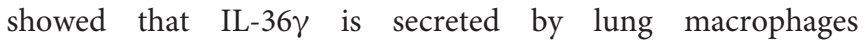
in an golgi-independent manner within vesicles and exosomes (43).

\section{FUNCTION OF IL-36}

The highest IL-36 activities probably are found at barrier sites of an organism (skin, lungs, and intestines). This indicates the importance of IL-36 cytokines in terms of protecting the body from the environment at its interfaces. The recognition of IL-36 $\alpha$, IL-36 $\beta$, and IL-36 $\gamma$ by IL-1R6 leads to the activation of pro-inflammatory pathways resulting in a higher anti-microbial activity of corresponding cells. This includes an increased maturation/differentiation of murine and human myeloid cells $(14,22,44-46)$, an increased bacterial clearance by murine macrophages in a sepsis-model (47), and an increased production of anti-microbial peptides by human keratinocytes (48). Furthermore, the production of proinflammatory mediators, such as cytokines and chemokines is induced by IL-36 receptor agonists in keratinocytes, Langerhans cells and macrophages. Among these mediators you can find cytokines, such as TNF, IL-6, and IL-8 (16, 49, 50), and chemokines, such as CXCL1, CXCL2, CXCL8, CCL3, CCL5, and 


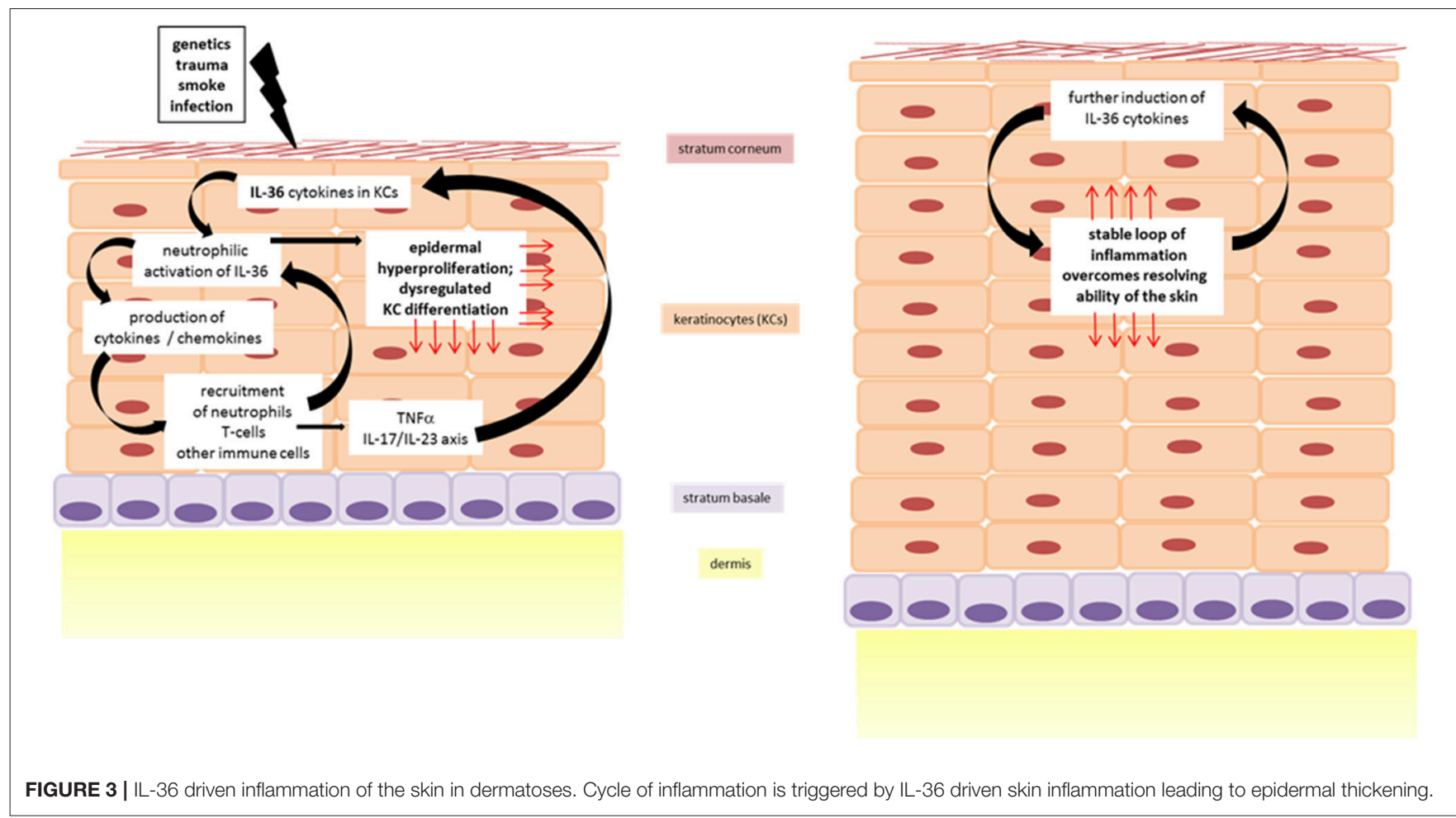

CCL20. IL-36 signaling leads to the recruitment of leukocytes in human skin and lungs of mice $(14,27)$. Members of the IL-36 family are thought to have an important role in bridging the innate and adaptive immune systems. They do not only recruit and activate cells of the innate immune system, but they also have indirect and direct effects on the proliferation and plasticity of adaptive immune cells. It was shown, that IL-36 signaling appears to have a beneficial effect on T-cell proliferation (14). Furthermore, it helps polarizing naïve T-helper cells toward T-helper 1 cells in an IL-2 mediated fashion (51). Harusato et al. demonstrated

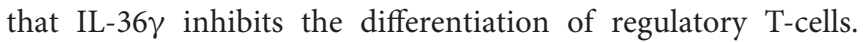
IL-36 $\gamma$ promotes the T-cell polarization toward T-helper 9 cells leading to a strong $\mathrm{T}$-cell driven inflammation of the intestine due to loss of self-tolerance (52). In contrast, other studies showed before a potential protective role of IL-36 $\gamma$ in acute intestinal inflammation. Mice lacking IL-1R6 showed a decreased resolution of intestinal damage after treatment with dextran sodium sulfate (28). The pro-inflammatory function of three agonistic IL-36 isoforms is opposed by IL-36 Ra, which has anti-inflammatory properties as a "natural inhibitor." IL-36 $\mathrm{Ra}$ has several anti-inflammatory effects including the reduction of IL-17 and IL-22 production in peripheral blood mononuclear cells after in vitro Stimulation with Candida (39). Furthermore, the treatment of murine liver cells with recombinant IL-36 $\mathrm{Ra}$ reduces the production of chemokines, such as CCL20 and therefore prevents from proper tissue regeneration in acetaminophen-induced liver damage (53). Taken together, these findings indicate that homeostasis of many tissues is based on the intact balance between IL36 receptor agonists and antagonists is essential for tissue homeostasis (54).

\section{IL-36 IN SKIN DISEASES}

As mentioned, an imbalance between the agonists and antagonists can lead to pathological changes. A dysregulation of both the pro-inflammatory IL-36 response and the antiinflammatory IL-36 response can lead to damage of the corresponding tissue due to unnaturally strong inflammation or due to a lack of self-limiting features. An increasing number of infectious triggers of IL-36 production has been identified. Different in vivo and in vitro experiments showed that the bacterium Pseudomonas aeruginosa (31), and the fungus Aspergillus fumigatus (55) are able to induce IL-36 cytokines in lung tissue. Interestingly, viral infections such as chronic hepatitis B can lead to elevated IL-36 levels in blood serum (56). There is far more data available on many different pathogens and tissues (especially in the lungs) than shown here. However, in this review we focus on the role of IL-36 $\alpha$, IL-36 $\beta$, IL-36 $\gamma$, and IL-36 Ra in various infectious and inflammatory skin diseases.

\section{IL-36 in Infectious Skin Diseases}

The family of IL-36 cytokines emerged from a common ancestor of IL- 1 to escape resistance strategies of microorganisms against IL- $1 \alpha$, IL- $1 \beta$ and IL-18 (57). Thus, it is a valuable evolutionary advantage to have this cytokine family. This hypothesis is 
supported by the fact that IL-36 cytokines are highly preserved within many species. The skin has a special significance within the host defense against microorganisms. It is colonized by many microbes and skin cells as well as immune cells have to distinguish between commensals and potentially pathogenic microorganisms (58).

\section{Bacterial Infections}

One of the most prominent skin germ that regularly leads to infections is Staphylococcus (S.) aureus. These gram-positive cocci colonize the skin of about $10-20 \%$ of the healthy population as part of the normal flora (59). A significant proportion of all skin and soft tissue infections in hospital patients are caused by $S$. aureus infection (60). So far, research has mainly focused on subepidermal $S$. aureus models. The skin defense against S. aureus depends on the IL-1 receptor and MyD88 (61). Subsequently, two groups published their work on epidermal colonization by $S$. aureus, considering the interplay between $S$. aureus and keratinocytes $(62,63)$. According to Liu et al. IL-36 $\alpha$ is predominantly produced upon superficial bacterial exposure, whereas IL- $1 \beta$ is produced after bacterial stimuli in deeper layers (63). Both groups describe phenol-soluble modulin $\alpha$ (PSM $\alpha)$ as the major virulence factor of $S$. aureus leading to the induction of IL-36 $\alpha$ in keratinocytes. In addition, IL-36 $\alpha$ induces an IL-17 mediated T-cell response promoting the inflammation of the skin. Colonization with $S$. aureus is particularly common in patients with atopic dermatitis (AD) (64). In most cases of a superinfected dermatitis there is a barrier defect in the skin, which enables the bacteria to invade. The order of events, whether the barrier defect of the skin is previously present or whether it is caused by bacteria, is still controversial. However, both events seem to favor each other and promote the inflammatory process. Antimicrobial therapies help to improve AD (65), which highlights the importance to consider superinfections of bacterial origins in dermatoses.

\section{Fungal Infections}

Similar to bacteria, there are also some fungal species that colonize humans as part of the skin flora and can lead to severe inflammations and diseases due to invasion (66). Also a fungal infection often occurs as a superinfection. For example, a large proportion of psoriasis patients additionally suffer from an infection with Candida species $(67,68)$. There is not much data concerning IL-36 expression in or by fungal infection of the skin, whereas psoriasis is a well-studied field of IL-

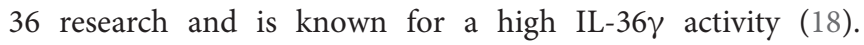
Braegelmann et al. investigated for the first time the IL-36 $\gamma$ expression in the context of psoriasis and fungal infections. In addition to the histomorphological similarity between psoriasis and certain fungal infections, it was shown that the fungus species Candida albicans and Trichophyton mentagrophytes are able to

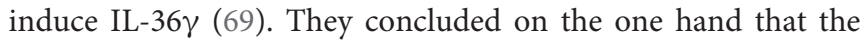
inflammation of psoriatic skin might be driven by fungi and, on the other hand that the clinical picture of psoriasis might be caused by a misdirected IL-36 $\gamma$ reaction, which was originally directed against fungal infections. Furthermore, it was shown that oral epithelial cells of mice react with increased IL-36 $\gamma$ expression after in vivo stimulation with candidalysin (70). IL-36 $\gamma$ has a leading role in the defense against and clearance of fungal skin infections $(69,70)$.

\section{Viral Infections}

Many viruses, such as poxvirus, measles virus, and several viruses from herpes virus family are affecting the skin. First evidence for a role of IL-36 signaling in viral infections emerged when Kumar et al. demonstrated the induction of IL-36 $\gamma$ in keratinocytes by an in vitro herpes simplex virus (HSV) infection (3). Some years later it was shown that IL-36 $\gamma$ is induced in keratinocytes (42) and in vaginal/cervical epithelial cells (71) by the RNA-analog poly(I:C), simulating a viral infection, which supported the assumption of antiviral functions of IL-36 cytokines. Recent studies have further investigated the protective role of pro-inflammatory IL-36 cytokines in herpes infections. Herpes infections are very common in the population. About $90 \%$ of the population carries HSV-1 and about 20-25\% HSV-2 (72). These viruses lead to an infection that persists for life and may have a very severe course under certain conditions. To date, there is no vaccination and no effective treatment available. Therefore, it is very important to understand the immunological processes of a herpes infection exactly. Milora et al. found increased levels of IL-36 $\alpha$ mRNA and IL-36 $\beta$ mRNA in HSV-1 infected mouse skin (73). In human keratinocytes, in vitro stimulation with HSV-1 led to the induction of IL-36 $\alpha$, but not to the induction of IL-36 $\beta$,

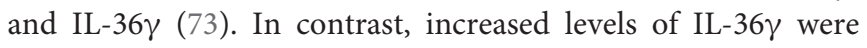
detected in vaginal epithelial cells upon HSV-2 infection (74). Subsequently, the application of exogenous IL-36 $\gamma$ in a threedimensional human vaginal epithelial cell model was tested for its antiviral functions. It was found that exogenous IL-36 $\gamma$ is able to inhibit viral replication and induce a stable antiviral environment (74). Treatment with IL-36 $\gamma$ led to the production of proinflammatory cytokines, antimicrobial peptides and chemokines (e.g., CCL20) and was thus identified as a protective shield against HSV-2 (74).

\section{IL-36 in Inflammatory Skin Diseases Psoriasis}

Psoriasis is a chronic, relapsing, inflammatory disease of the skin. Even if the symptoms mainly affect the skin, they often also manifest in other parts of the body. Nail psoriasis causes nails changes and is thought to be a precursor of psoriatic arthritis which itself is manifested in the joints (75). Among psoriasis patients there is an increased risk of developing systemic comorbidities, such as cardiovascular disease (76) or metabolic syndrome (77). Although it is difficult to give correct information on epidemiology, it is often reported as $2 \%$ of the world's population (78). This difficulty could be explained by the fact that there is no clear clinical picture of psoriasis, but rather a spectrum of disease. Psoriasis palmoplantaris affects the palms of the hands and feet, psoriasis inversa the skin folds on the armpits and buttocks, and psoriasis capitis the scalp. The morphology of the skin alterations ranges from comparatively mild plaques, as they are found in the psoriasis vulgaris, over single, sterile, purulent blisters in pustular psoriasis, up to generalized pustular psoriasis (GPP), in which pus blisters occur extensively. GPP is 
known as the maximum and most severe variant of psoriasis and sometimes life-threatening. The disease of GPP is based on a missense mutation in the gene encoding for IL-36 Ra. Deficiency of IL-36 Ra (DITRA) results in a biochemically instable protein as well as disturbed receptor activity (Figure 2) (79-81). The pustular forms of psoriasis are characterized by a high genetic eruption pressure, which is why often small triggers (smoking, infections) are sufficient to elicit the disease. Since IL-38 was identified as another potent IL-1R6 antagonist, its role in psoriasis was currently investigated. IL-38 is downregulated in psoriasis patients and this correlates with disease severity (82). This study showed that both IL-38 and IL-36 Ra are able to reduce most of IL-36 $\gamma$ induced inflammatory processes in vitro in keratinocytes (82). Furthermore, pre-treatment with these antagonists a protective effect in imiquimod-induced psoriasis and saves mice from severe disease phenotype (82). Not only the loss of antagonistic activity, but also an increased agonistic activity at IL-1R6 is strongly associated with psoriasis. Gene expression analyses revealed an upregulation of all IL-36 family members $(49,83)$ but especially of the agonists IL-36 $\alpha$ an IL-36 $\gamma$ (20). Interestingly, the isoform IL-36 $\gamma$ appears to play a specific role in psoriasis (18). The protein expression level of IL-36 $\gamma$ was up to three times higher in psoriatic lesions compared to other (inflammatory) skin disorders, such as atopic dermatitis (AD), lichen planus, contact eczema, pityriasis lichenoides, subacute cutaneous lupus erythematosus, and mycosis fungoides. The IL-36 $\gamma$ expression correlates with disease activity and decreases during TNF $\alpha$ treatment, which improves the disease (18). These findings indicate that IL-36 $\gamma$ is a potential biomarker for identification of psoriasis and monitoring of the disease course. It has been assumed for a long time that keratinocytes are the main modulators of psoriasis. However, it was found that a T-cell mediated immune reaction via the IL-17/IL-23/IL-22 axis including a significant importance of $\gamma \delta$ T-cells contributes to the inflammation of the skin $(84,85)$. IL-36 cytokines are thought to be regulated by the IL-17/IL-23 axis during the course of psoriasis (16). Characteristics of psoriatic skin are an increased proliferation and impaired differentiation of keratinocytes. Pfaff et al. demonstrated within a three-dimensional skin equivalent that IL-36 cytokines are induced by IL-17 which results in the inhibition of keratinocyte differentiation. These findings indicate that an autocrine feedback loop between IL-36 cytokines and IL17 contribute to the histological findings of epidermal thickening

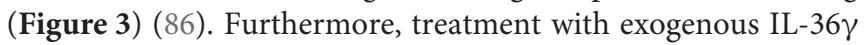
leads to a decreased expression of differentiation markers on keratinocytes $(86,87)$. In this context, Wang et al. identified the Wnt-signaling pathway as the responsible cascade for the altered differentiation and increased inflammation of keratinocytes in psoriasis (87). By the example of psoriasis, the importance of an intact balance between pro-inflammatory and anti-inflammatory processes becomes clear once more. Not only the deficiency of the receptor antagonist, as it is the case in GPP, leads to a disturbed balance. Also the hyper activation of IL-36 receptor agonists, such as an overexpression of IL-36 $\alpha$, which in transgenic mice led to psoriasis phenotype (15), interrupts the necessary homeostasis. There is an urgent need of understanding the underlying pathways. All these findings indicate that both IL-36 receptor agonists and antagonists represent potent therapeutic targets in the treatment of psoriasis patients.

\section{IL-36 in Other Inflammatory Diseases}

The prominent role of IL-36 in psoriasis raises the question whether IL-36 cytokines are of comparable importance in other inflammatory skin diseases. However, there are only few and partly contradictory data. A study whose cohort suffered from psoriasis and atopic dermatitis (AD) at the same time examined the intraindividual expression differences of psoriasis and $\mathrm{AD}$ lesions. Biopsies were taken from $\mathrm{AD} /$ psoriatic skin lesions and from non-lesional skin. As their RNA profiles were compared the IL-36 cytokine family was identified as "psoriasis-specific" (83). In contrast, another study reports an increased expression

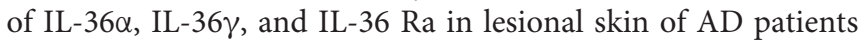
compared to non-lesional skin (88). Furthermore, an increased expression of all pro-inflammatory and anti-inflammatory IL-36 isoforms was demonstrated in the lesions of patients with allergic dermatitis by qPCR (89). Zebrowska et al. investigated on the involvement of IL-36 cytokines in the pathogenesis of some blistering diseases. They found significantly increased levels of IL-36 $\alpha$ in correlation with a higher production of IL-17 in patients with bullous pemphigoid, pemphigus vulgaris, and dermatitis herpetiformis (90). Additionally, they describe a positive correlation between IL-36 $\alpha$ and antibodies directed against transglutaminase which is the major autoantigen in dermatitis herpetiformis (90). With regard to inflammatory skin disorders the data is mostly limited to psoriasis. However, currently the discovery of new relationships is contributing to a better understanding of IL-36 itself and the associated diseases in order to treat or even prevent them.

\section{IL-36 AS A THERAPEUTIC TARGET}

Inflammatory, non-infectious dermatoses are often treated non-specifically with anti-inflammatory agents such as corticosteroids. In the case of psoriasis, glucocorticosteroids and vitamin D3 derivatives are considered to be most effective. They are given either alone or in combination and either topically or systemically depending on the severity of the disease (91). These therapies were already used before molecular players of the disease were known. Recent studies show that these agents have an influence on the feedback loop between IL-36 $\alpha$ or IL-36 $\gamma$ and the IL-23/IL-17 axis (92). It was shown in a murine psoriasis model that the vitamin D3 derivative calcipotriol inhibits the expression of IL-36 $\alpha$ and IL-36 $\gamma$ in keratinocytes via their vitamin $\mathrm{D}$ receptor, which in turn prevents the infiltration of neutrophils (92) and saves skin from inflammation. Therapies used for more severe variants of dermatoses target the major pro-inflammatory cytokines, like IL-1 or TNF $\alpha$ and include immunomodulatory features $(93,94)$. The IL-36 cytokine family is part of the IL-1 superfamily. There are case reports in which patients suffering from GPP through DITRA have been successfully treated with Anakinra, a recombinant IL-1 receptor antagonist as a immunosuppressive agent (95-98). However, these cases were discussed as individual cases and the development of IL-36 specific therapies is requested (99). 
Systemic administration of any therapeutics can have severe side effects, which is why the research on even more specific, preferably non-systemic therapies is intensifying. It was shown that both specific (humanized) antibodies against the murine and human IL-1R6, as well as antagonistic substances of recombinant origin, lead to a reduced inflammatory response $(100,101)$. These results were proofed in vitro by determination of reduced production of IL-17 by keratinocytes and in vivo by determination of reduced skin thickening of mouse ears. Another therapeutic strategy aims to reduce the activity of the pro-inflammatory IL-36 receptor agonists by therapeutically inhibit the activating proteases cathepsin $G$ and elastase. In contrast to former existing small-molecule inhibitors, which inactivate protease activities individually, Sullivan et al. identified bispecific peptide-based molecules, so-called "pseudosubstrates" that are able to antagonize the protease activity of both cathepsin G (usually would activate IL-36 $\alpha$ and IL-36 $\beta$ ) and elastase

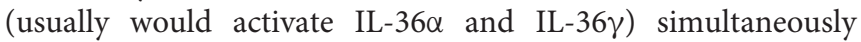

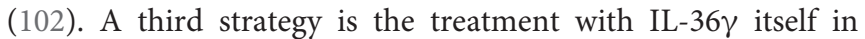
terms of using its protective potential. It was shown in a mouse model that this treatment led to an antiviral environment. After infection HSV-2, the disease occurred significantly delayed with comparatively milder symptoms in mice which received IL-36 $\gamma$ (74). In this context, an increased and transient production of important immune mediators was observed, such as IL-36 $\gamma$ itself, IL-1 $\beta$, IL-6, CCL20, CXCL1, and the antimicrobial peptide secretory leukocyte peptidase inhibitor (Slpi). The approaches aim to interrupt the IL-36 cascade in order to attenuate the inflammatory process. It is obvious that there is still a great potential to develop effective IL-36 related therapies and to conduct clinical studies on tolerability and efficiency. Life quality of dermatitis patients is diminished on one hand by the symptoms of the disease, but also frequently by social stigmatization. Therefore, there is a great need for therapy in the area of inflammatory dermatoses, whereby the cytokine family IL-36 seems to be an attractive target.

\section{CONCLUSION AND FUTURE ISSUES}

IL-36 signaling is similarly to other members of IL-1 cytokine superfamily an effective first line defense mechanism. In contrast to the more general occurrence of IL-1 activity, the

\section{REFERENCES}

1. Mulero JJ, Pace AM, Nelken ST, Loeb DB, Correa TR, Drmanac $\mathrm{R}$, et al. IL1HY1: A novel interleukin-1 receptor antagonist gene. Biochem Biophys Res Commun. (1999) 263:702-6. doi: 10.1006/bbrc. 1999.1440

2. Smith DE, Renshaw BR, Ketchem RR, Kubin M, Garka KE, Sims JE. Four new members expand the interleukin-1 superfamily. J Biol Chem. (2000) 275:1169-75. doi: 10.1074/jbc.275.2.1169

3. Kumar S, McDonnell PC, Lehr R, Tierney L, Tzimas MN, Griswold $\mathrm{DE}$, et al. Identification and initial characterization of four novel members of the interleukin-1 family. J Biol Chem. (2000) 275:1030814. doi: $10.1074 /$ jbc. 275.14 .10308
IL-36 associated immune response mainly takes place at the interfaces of an organism (intestines, lungs and skin). IL-36 emerges as the "optimized" version of a common ancestor and protects the organism at the corresponding sites against invasion of undesirable or even dangerous microorganisms. IL-36 cytokines regulate themselves by its natural antagonists, IL-36 $\mathrm{Ra}$ and IL-38, which prevents from hyper inflammation of the corresponding tissue in a healthy state. Signaling through IL-1R6 activates cascades including prominent proinflammatory transcription factors resulting in the production of pro-inflammatory cytokines, chemokines, and antimicrobial peptides. Finally, an inflammation is induced aiming the clearance of infections. As in any system with many players, a lot can go wrong. This potentially results in a disease. The responsible triggers and the molecular basis of existing forms of infectious and/or inflammatory dermatitis are highly variable and are not fully understood yet. It is striking that the different isoforms IL-36 $\alpha$, IL-36 $\beta$, and IL-36 $\gamma$ are expressed differently under physiological as well as pathological conditions, although they basically have the same function. IL-36, with all its isoforms, is of great importance for the therapy of various dermatoses and also serves as a diagnostic tool in dermatology. It is very important to understand that IL-36 is bridging the innate and adaptive immune systems. Antagonizing the pro-inflammatory IL-36 cytokines was experimentally shown to be an effective treatment of dermatitis, like psoriasis. However, it is advisable to not only consider antagonizing the pro-inflammatory isoforms in order to reduce hyper inflammations but also use their

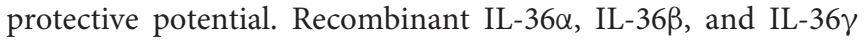
are potentially able to make barrier sites more resistant to the invasion of unwanted microorganisms. However, possible side effects of both approaches must be tested. We are at an early stage of research on treatment strategies involving IL-36 cytokines. There is still much to learn about this exciting cytokine family. There is a lot of diagnostic and therapeutic potential to be exploited, which could bring relief to many patients affected by dermatoses.

\section{AUTHOR CONTRIBUTIONS}

All authors listed have made a substantial, direct and intellectual contribution to the work, and approved it for publication.
4. Sims JE, Nicklin MJ, Bazan JF, Barton JL, Busfield SJ, Ford JE, et al. A new nomenclature for IL-1-family genes. Trends Immunol. (2001) 22:5367. doi: 10.1016/S1471-4906(01)02040-3

5. Dinarello C, Arend W, Sims J, Smith D, Blumberg H, O’Neill L, et al. IL-1 family nomenclature. Nat Immunol. (2010) 11:973. doi: 10.1038/ni1110-973

6. Towne JE, Garka KE, Renshaw BR, Virca GD, Sims JE. Interleukin (IL)-1F6, IL-1F8, and IL-1F9 signal through IL-1Rrp2 and IL-1RAcP to activate the pathway leading to NF-kappaB and MAPKs. J Biol Chem. (2004) 279:1367788. doi: 10.1074/jbc.M400117200

7. Debets R, Timans JC, Homey B, Zurawski S, Sana TR, Lo S, et al. Two novel IL-1 family members, IL- $1 \delta$ and IL- $1 \epsilon$, function as an antagonist and agonist of NF- $\kappa$ B activation through the orphan IL-1 receptor-related protein $2 . J$ Immunol. (2001) 167:1440-6. doi: 10.4049/jimmunol.167.3.1440 
8. Dunn E, Sims JE, Nicklin MJ, O’Neill LA. Annotating genes with potential roles in the immune system: six new members of the IL-1 family. Trends Immunol. (2001) 22:533-6. doi: 10.1016/S1471-4906(01) 02034-8

9. Mulero JJ, Nelken ST, Ford JE. Organization of the human interleukin1 receptor antagonist gene IL1HY1. Immunogenetics. (2000) 51:4258. doi: 10.1007/s002510050640

10. Nolan KF, Greaves DR, Waldmann H. The human interleukin 18 gene IL18 maps to 11q22.2-q22.3, closely linked to the DRD2 gene locus and distinct from mapped IDDM loci. Genomics. (1998) 51:1613. doi: 10.1006/geno.1998.5336

11. Nishida A, Hidaka K, Kanda $T$, Imaeda $H$, Shioya $M$, Inatomi $O$, et al. Increased expression of interleukin-36, a member of the interleukin-1 cytokine family, in inflammatory bowel disease. Inflamm Bowel Dis. (2016) 22:303-14. doi: 10.1097/MIB.0000000000000654

12. Russell SE, Horan RM, Stefanska AM, Carey A, Leon G, Aguilera $\mathrm{M}$, et al. IL-36 $\alpha$ expression is elevated in ulcerative colitis and promotes colonic inflammation. Mucosal Immunol. (2016) 9:1193-204. doi: 10.1038/mi.2015.134

13. Frey S, Derer A, Messbacher M-E, Baeten DL, Bugatti S, Montecucco $\mathrm{C}$, et al. The novel cytokine interleukin-36 $\alpha$ is expressed in psoriatic and rheumatoid arthritis synovium. Ann Rheum Dis. (2013) 72:156974. doi: 10.1136/annrheumdis-2012-202264

14. Foster AM, Baliwag J, Chen CS, Guzman AM, Stoll SW, Gudjonsson JE, et al. IL-36 promotes myeloid cell infiltration, activation, and inflammatory activity in skin. J Immunol. (2014) 192:6053-61. doi: 10.4049/jimmunol.1301481

15. Blumberg $\mathrm{H}$, Dinh $\mathrm{H}$, Trueblood ES, Pretorius J, Kugler D, Weng $\mathrm{N}$, et al. Opposing activities of two novel members of the IL-1 ligand family regulate skin inflammation. J Exp Med. (2007) 204:260314. doi: 10.1084/jem.20070157

16. Carrier Y, Ma H-L, Ramon HE, Napierata L, Small C, O’Toole M, et al. Inter-regulation of Th17 cytokines and the IL-36 cytokines in vitro and in vivo: implications in psoriasis pathogenesis. J Invest Dermatol. (2011) 131:2428-37. doi: 10.1038/jid.2011.234

17. Towne JE, Sims JE. IL-36 in psoriasis. Curr Opin Pharmacol. (2012) 12:48690. doi: 10.1016/j.coph.2012.02.009

18. D'Erme AM, Wilsmann-Theis D, Wagenpfeil J, Hölzel M, Ferring-Schmitt S, Sternberg S, et al. IL-36 $\gamma$. (IL-1F9) is a biomarker for psoriasis skin lesions. $J$ Invest Dermatol. (2015) 135:1025-32. doi: 10.1038/jid.2014.532

19. Gresnigt MS, van de Veerdonk FL. Biology of IL-36 cytokines and their role in disease. Semin Immunol. (2013) 25:45865. doi: 10.1016/j.smim.2013.11.003

20. Boutet M-A, Bart G, Penhoat M, Amiaud J, Brulin B, Charrier C, et al. Distinct expression of interleukin (IL) $-36 \alpha, \beta$ and $\gamma$, their antagonist IL-36Ra and IL-38 in psoriasis, rheumatoid arthritis and Crohn's disease. Clin Exp Immunol. (2016) 184:159-73. doi: 10.1111/cei.12761

21. Chustz RT, Nagarkar DR, Poposki JA, Favoreto S, Avila PC, Schleimer RP, et al. Regulation and function of the IL-1 family cytokine IL-1F9 in human bronchial epithelial cells. Am J Respir Cell Mol Biol. (2011) 45:14553. doi: 10.1165/rcmb.2010-0075OC

22. Vigne S, Palmer G, Lamacchia C, Martin P, Talabot-Ayer D, Rodriguez E, et al. IL-36R ligands are potent regulators of dendritic and T cells. Blood. (2011) 118:5813-23. doi: 10.1182/blood-2011-05-356873

23. Yang J, Meyer M, Müller A-K, Böhm F, Grose R, Dauwalder T, et al. Fibroblast growth factor receptors 1 and 2 in keratinocytes control the epidermal barrier and cutaneous homeostasis. J Cell Biol. (2010) 188:93552. doi: 10.1083/jcb.200910126

24. Franzke C-W, Cobzaru C, Triantafyllopoulou A, Löffek S, Horiuchi K, Threadgill DW, et al. Epidermal ADAM17 maintains the skin barrier by regulating EGFR ligand-dependent terminal keratinocyte differentiation. $J$ Exp Med. (2012) 209:1105-19. doi: 10.1084/jem.20112258

25. Towne JE, Renshaw BR, Douangpanya J, Lipsky BP, Shen M, Gabel CA, et al. Interleukin-36 (IL-36) ligands require processing for full agonist (IL-36 $\alpha$,

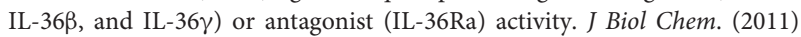
286:42594-602. doi: 10.1074/jbc.M111.267922

26. Henry CM, Sullivan GP, Clancy DM, Afonina IS, Kulms D, Martin SJ. Neutrophil-derived proteases escalate inflammation through activation of IL-36 family cytokines. Cell Rep. (2016) 14:708-22. doi: 10.1016/j.celrep.2015.12.072

27. Ramadas RA, Ewart SL, Iwakura Y, Medoff BD, LeVine AM. IL-36 $\alpha$ exerts pro-inflammatory effects in the lungs of mice. PLOS ONE. (2012) 7:e45784. doi: 10.1371/journal.pone.0045784

28. Medina-Contreras O, Harusato A, Nishio H, Flannigan KL, Ngo V, Leoni G, et al. Cutting edge: IL-36 receptor promotes resolution of intestinal damage. J Immunol. (2016) 196:34-8. doi: 10.4049/jimmunol.1501312

29. Berglöf E, Andre R, Renshaw BR, Allan SM, Lawrence CB, Rothwell NJ, et al. IL-1Rrp2 expression and IL-1F9 (IL-1H1) actions in brain cells. $J$ Neuroimmunol. (2003) 139:36-43. doi: 10.1016/S0165-5728(03)00130-9

30. Costelloe C, Watson M, Murphy A, McQuillan K, Loscher C, Armstrong ME, et al. IL-1F5 mediates anti-inflammatory activity in the brain through induction of IL-4 following interaction with SIGIRR/TIR8. J Neurochem. (2008) 105:1960-9. doi: 10.1111/j.1471-4159.2008.05304.x

31. Vos JB, van Sterkenburg MA, Rabe KF, Schalkwijk J, Hiemstra PS, Datson NA. Transcriptional response of bronchial epithelial cells to Pseudomonas aeruginosa: identification of early mediators of host defense. Physiol Genomics. (2005) 21:324-36. doi: 10.1152/physiolgenomics.00289.2004

32. Macleod T, Doble R, McGonagle D, Wasson CW, Alase A, Stacey $\mathrm{M}$, et al. Neutrophil Elastase-mediated proteolysis activates the antiinflammatory cytokine IL-36 Receptor antagonist. Sci Rep. (2016) 6:24880. doi: $10.1038 /$ srep24880

33. Bachmann M, Scheiermann P, Härdle L, Pfeilschifter J, Mühl H. IL-36 $/$ IL1F9, an innate T-bet target in myeloid cells. J Biol Chem. (2012) 287:4168496. doi: 10.1074/jbc.M112.385443

34. Takaishi M, Satoh T, Akira S, Sano S. Regnase-1, an Immunomodulator, Limits the IL-36/IL-36R Autostimulatory Loop in Keratinocytes to Suppress Skin Inflammation. J Invest Dermatol. (2018) 138:1439-42. doi: 10.1016/j.jid.2017.12.033

35. Swindell WR, Beamer MA, Sarkar MK, Loftus S, Fullmer J, Xing X, et al. RNA-Seq Analysis of IL-1B and IL-36 Responses in Epidermal Keratinocytes Identifies a Shared MyD88-Dependent Gene Signature. Front Immunol. (2018) 9:80. doi: 10.3389/fimmu.2018.00080

36. Barksby HE, Nile CJ, Jaedicke KM, Taylor JJ, Preshaw PM. Differential expression of immunoregulatory genes in monocytes in response to Porphyromonas gingivalis and Escherichia coli lipopolysaccharide. Clin Exp Immunol. (2009) 156:479-87. doi: 10.1111/j.1365-2249.2009.03920.x

37. Mori K, Fujisawa T, Kusagaya H, Yamanaka K, Hashimoto D, Enomoto $\mathrm{N}$, et al. Synergistic proinflammatory responses by IL-17A and tolllike receptor 3 in human airway epithelial cells. PLOS ONE. (2015) 10:e0139491. doi: 10.1371/journal.pone.0139491

38. Boraschi D, Tagliabue A. The interleukin-1 receptor family. Semin Immunol. (2013) 25:394-407. doi: 10.1016/j.smim.2013.10.023

39. van de Veerdonk FL, Stoeckman AK, Wu G, Boeckermann AN, Azam T, Netea MG, et al. IL-38 binds to the IL-36 receptor and has biological effects on immune cells similar to IL-36 receptor antagonist. Proc Natl Acad Sci USA. (2012) 109:3001-5. doi: 10.1073/pnas.1121534109

40. Clancy DM, Henry CM, Sullivan GP, Martin SJ. Neutrophil extracellular traps can serve as platforms for processing and activation of IL-1 family cytokines. FEBS J. (2017) 284:1712-25. doi: 10.1111/febs.14075

41. Martin U, Scholler J, Gurgel J, Renshaw B, Sims JE, Gabel CA. Externalization of the leaderless cytokine IL-1F6 occurs in response to lipopolysaccharide/ATP activation of transduced bone marrow macrophages. J Immunol. (2009) 183:402130. doi: 10.4049/jimmunol.0803301

42. Lian L-H, Milora KA, Manupipatpong KK, Jensen LE. The doublestranded RNA analogue polyinosinic-polycytidylic acid induces keratinocyte

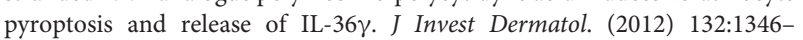
53. doi: 10.1038/jid.2011.482

43. Kovach MA, Singer BH, Newstead MW, Zeng X, Moore TA, White ES, et al. IL-36 $\gamma$ is secreted in microparticles and exosomes by lung macrophages in response to bacteria and bacterial components. J Leukoc Biol. (2016) 100:413-21. doi: 10.1189/jlb.4A0315-087R

44. Mutamba S, Allison A, Mahida Y, Barrow P, Foster N. Expression of IL1Rrp2 by human myelomonocytic cells is unique to DCs and facilitates DC maturation by IL-1F8 and IL-1F9. Eur J Immunol. (2012) 42:60717. doi: $10.1002 /$ eji. 201142035 
45. Higgins J, Mutamba S, Mahida Y, Barrow P, Foster N. IL-36 $\alpha$ induces maturation of Th1-inducing human MDDC and synergises with IFN- $\gamma$ to induce high surface expression of CD14 and CD11c. Hum Immunol. (2015) 76:245-53. doi: 10.1016/j.humimm.2015.01.012

46. Saha SS, Singh D, Raymond EL, Ganesan R, Caviness G, Grimaldi $\mathrm{C}$, et al. Signal Transduction and Intracellular Trafficking by the Interleukin 36 Receptor. J Biol Chem. (2015) 290:239974006. doi: 10.1074/jbc.M115.653378

47. Tao X, Song Z, Wang C, Luo H, Luo Q, Lin X, et al. Interleukin $36 \alpha$ Attenuates Sepsis by Enhancing Antibacterial Functions of Macrophages. J Infect Dis. (2017) 215:321-32. doi: 10.1093/infdis/jiw535

48. Nguyen TT, Niyonsaba F, Ushio H, Akiyama T, Kiatsurayanon C, Smithrithee $\mathrm{R}$, et al. Interleukin-36 cytokines enhance the production of host defense peptides psoriasin and LL-37 by human keratinocytes through activation of MAPKs and NF-кB. J Dermatol Sci. (2012) 68:636. doi: 10.1016/j.jdermsci.2012.07.010

49. Johnston A, Xing X, Guzman AM, Riblett M, Loyd CM, Ward NL, et al. IL1F5, -F6, -F8, and -F9: a novel IL-1 family signaling system that is active in psoriasis and promotes keratinocyte antimicrobial peptide expression. $J$ Immunol. (2011) 186:2613-22. doi: 10.4049/jimmunol.1003162

50. Dietrich D, Martin P, Flacher V, Sun Y, Jarrossay D, Brembilla N, et al. Interleukin-36 potently stimulates human M2 macrophages, Langerhans cells and keratinocytes to produce pro-inflammatory cytokines. Cytokine. (2016) 84:88-98. doi: 10.1016/j.cyto.2016.05.012

51. Vigne S, Palmer G, Martin P, Lamacchia C, Strebel D, Rodriguez E, et al. IL-36 signaling amplifies Th1 responses by enhancing proliferation and Th1 polarization of naive CD4+ T cells. Blood. (2012) 120:347887. doi: 10.1182/blood-2012-06-439026

52. Harusato A, Abo H, Ngo VL, Yi SW, Mitsutake K, Osuka S, et al. IL$36 \gamma$ signaling controls the induced regulatory $\mathrm{T}$ cell-Th9 cell balance via NFKB activation and STAT transcription factors. Mucosal Immunol. (2017) 10:1455-67. doi: 10.1038/mi.2017.21

53. Scheiermann P, Bachmann M, Härdle L, Pleli T, Piiper A, Zwissler B, et al. Application of IL-36 receptor antagonist weakens CCL20 expression and impairs recovery in the late phase of murine acetaminophen-induced liver injury. Sci Rep. (2015) 5:8521. doi: 10.1038/srep08521

54. Palomo J, Dietrich D, Martin P, Palmer G, Gabay C. The interleukin (IL)-1 cytokine family-Balance between agonists and antagonists in inflammatory diseases. Cytokine. (2015) 76:25-37. doi: 10.1016/j.cyto.2015.06.017

55. Gresnigt MS, Rösler B, Jacobs CW, Becker KL, Joosten LA, van der Meer JW, et al. The IL-36 receptor pathway regulates Aspergillus fumigatusinduced Th1 and Th17 responses. Eur J Immunol. (2013) 43:41626. doi: 10.1002/eji.201242711

56. Gong Y, Tingxi Z, Qing L, Guozhen Z, Bing T, Xiaoliang Y, et al. Elevated production of IL-36 $\alpha$ in chronic hepatitis B virus-infected patients correlates with viral load. Microb Pathog. (2017) 113:4125. doi: 10.1016/j.micpath.2017.11.023

57. Jensen LE. Interleukin-36 cytokines may overcome microbial immune evasion strategies that inhibit interleukin-1 family signaling. Sci Signal. (2017) 10:eaan3589. doi: 10.1126/scisignal.aan3589

58. Segre JA. Epidermal barrier formation and recovery in skin disorders. J Clin Invest. (2006) 116:1150-8. doi: 10.1172/JCI28521

59. Lowy FD. Staphylococcus aureus infections. N Engl J Med. (1998) 339:52032. doi: 10.1056/NEJM199808203390806

60. Moran GJ, Krishnadasan A, Gorwitz RJ, Fosheim GE, McDougal LK, Carey RB, et al. Methicillin-resistant S. aureus infections among patients in the emergency department. N Engl J Med. (2006) 355:66674. doi: 10.1056/NEJMoa055356

61. Miller LS, O'Connell RM, Gutierrez MA, Pietras EM, Shahangian A, Gross $\mathrm{CE}$, et al. MyD88 mediates neutrophil recruitment initiated by IL-1R but not TLR2 activation in immunity against Staphylococcus aureus. Immunity. (2006) 24:79-91. doi: 10.1016/j.immuni.2005.11.011

62. Nakagawa S, Matsumoto M, Katayama Y, Oguma R, Wakabayashi S, Nygaard T, et al. Staphylococcus aureus virulent PSM $\alpha$ peptides induce keratinocyte alarmin release to orchestrate IL-17-dependent skin inflammation. Cell Host Microbe. (2017) 22:667-677.e5. doi: 10.1016/j.chom.2017.10.008

63. Liu H, Archer NK, Dillen CA, Wang Y, Ashbaugh AG, Ortines RV, et al. Staphylococcus aureus epicutaneous exposure drives skin inflammation via IL-36-mediated T cell responses. Cell Host Microbe. (2017) 22:653666.e5. doi: 10.1016/j.chom.2017.10.006

64. Kong HH, Oh J, Deming C, Conlan S, Grice EA, Beatson MA, et al. Temporal shifts in the skin microbiome associated with disease flares and treatment in children with atopic dermatitis. Genome Res. (2012) 22:8509. doi: 10.1101/gr.131029.111

65. Huang JT, Abrams M, Tlougan B, Rademaker A, Paller AS. Treatment of Staphylococcus aureus colonization in atopic dermatitis decreases disease severity. Pediatrics. (2009) 123:e808-14. doi: 10.1542/peds.2008-2217

66. El-Jurdi N, Ghannoum M. The mycobiome: impact on health and disease states. In: Heitman J, Howlett B, Crous P, Stukenbrock E, James T, Gow N, editors. The Fungal Kingdom. Washington, DC: ASM Press (2017). p. 845-54. doi: 10.1128/microbiolspec.FUNK-0045-2016

67. Waldman A, Gilhar A, Duek L, Berdicevsky I. Incidence of Candida in psoriasis-a study on the fungal flora of psoriatic patients. Mycoses. (2001) 44(3-4):77-81.

68. Taheri Sarvtin M, Shokohi T, Hajheydari Z, Yazdani J, Hedayati MT. Evaluation of candidal colonization and specific humoral responses against Candida albicans in patients with psoriasis. Int J Dermatol. (2014) 53:e55560. doi: 10.1111/ijd.12562

69. Braegelmann J, Braegelmann C, Bieber T, Wenzel J. Candida induces the expression of IL-36 $\gamma$ in human keratinocytes: implications for a pathogendriven exacerbation of psoriasis? J Eur Acad Dermatol Venereol. (2018) 32:e403-6. doi: 10.1111/jdv.14994

70. Verma AH, Zafar H, Ponde NO, Hepworth OW, Sihra D, Aggor FE, et al. IL-36 and IL-1/IL-17 drive immunity to oral candidiasis via parallel mechanisms. J Immunol. (2018) 201:627-34. doi: 10.4049/jimmunol.1800515

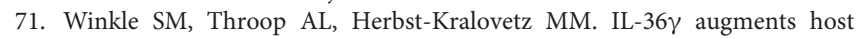
defense and immune responses in human female reproductive tract epithelial cells. Front Microbiol. (2016) 7:955. doi: 10.3389/fmicb.2016.00955

72. Kollias CM, Huneke RB, Wigdahl B, Jennings SR. Animal models of herpes simplex virus immunity and pathogenesis. J Neurovirol. (2015) 21:823. doi: 10.1007/s13365-014-0302-2

73. Milora KA, Uppalapati SR, Sanmiguel JC, Zou W, Jensen LE. Interleukin$36 \beta$ provides protection against HSV-1 infection, but does not modulate initiation of adaptive immune responses. Sci Rep. (2017) 7:5799. doi: 10.1038/s41598-017-05363-4

74. Gardner JK, Herbst-Kralovetz MM. IL-36 $\gamma$ induces a transient HSV-2 resistant environment that protects against genital disease and pathogenesis. Cytokine. (2018) 111:63-71. doi: 10.1016/j.cyto.2018.07.034

75. Raposo I, Torres T. Nail psoriasis as a predictor of the development of psoriatic arthritis. Actas Dermosifiliogr. (2015) 106:452-7. doi: 10.1016/j.ad.2015.02.005

76. Gu W-J, Weng C-L, Zhao Y-T, Liu Q-H, Yin R-X. Psoriasis and risk of cardiovascular disease: a meta-analysis of cohort studies. Int J Cardiol. (2013) 168:4992-6. doi: 10.1016/j.ijcard.2013.07.127

77. Armstrong AW, Harskamp CT, Armstrong EJ. Psoriasis and metabolic syndrome: a systematic review and meta-analysis of observational studies. J Am Acad Dermatol. (2013) 68:654-62. doi: 10.1016/j.jaad.2012.08.015

78. Christophers E. Psoriasis - epidemiology and clinical spectrum. Clin Exp Dermatol. (2001) 26:314-20. doi: 10.1046/j.1365-2230.2001.00832.x

79. Marrakchi S, Guigue P, Renshaw BR, Puel A, Pei X-Y, Fraitag S, et al. Interleukin-36-receptor antagonist deficiency and generalized pustular psoriasis. N Engl J Med. (2011) 365:620-8. doi: 10.1056/NEJMoa1013068

80. Onoufriadis A, Simpson MA, Pink AE, Di Meglio P, Smith CH, Pullabhatla $\mathrm{V}$, et al. Mutations in IL36RN/IL1F5 are associated with the severe episodic inflammatory skin disease known as generalized pustular psoriasis. Am J Hum Genet. (2011) 89:432-7. doi: 10.1016/j.ajhg.2011.07.022

81. Farooq M, Nakai H, Fujimoto A, Fujikawa H, Matsuyama A, Kariya $\mathrm{N}$, et al. Mutation analysis of the IL36RN gene in 14 Japanese patients with generalized pustular psoriasis. Hum Mutat. (2013) 34:17683. doi: 10.1002/humu.22203

82. Mercurio L, Morelli M, Scarponi C, Eisenmesser EZ, Doti N, Pagnanelli G, et al. IL-38 has an anti-inflammatory action in psoriasis and its expression correlates with disease severity and therapeutic response to antiIL-17A treatment. Cell Death Dis. (2018) 9:1104. doi: 10.1038/s41419-0181143-3 
83. Quaranta M, Knapp B, Garzorz N, Mattii M, Pullabhatla V, Pennino $\mathrm{D}$, et al. Intraindividual genome expression analysis reveals a specific molecular signature of psoriasis and eczema. Sci Transl Med. (2014) 6:244ra90. doi: 10.1126/scitranslmed.3008946

84. Lew W, Bowcock AM, Krueger JG. Psoriasis vulgaris: cutaneous lymphoid tissue supports T-cell activation and "Type 1" inflammatory gene expression. Trends Immunol. (2004) 25:295-305. doi: 10.1016/j.it.2004.03.006

85. Tortola L, Rosenwald E, Abel B, Blumberg H, Schäfer M, Coyle AJ, et al. Psoriasiform dermatitis is driven by IL-36-mediated DC-keratinocyte crosstalk. J Clin Invest. (2012) 122:3965-76. doi: 10.1172/JCI63451

86. Pfaff CM, Marquardt Y, Fietkau K, Baron JM, Lüscher B. The psoriasisassociated IL-17A induces and cooperates with IL-36 cytokines to control keratinocyte differentiation and function. Sci Rep. (2017) 7:15631. doi: 10.1038/s41598-017-15892-7

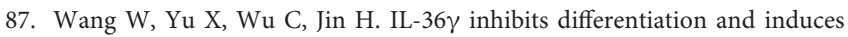
inflammation of keratinocyte via Wnt signaling pathway in psoriasis. Int $J$ Med Sci. (2017) 14:1002-7. doi: 10.7150/ijms.20809

88. Suárez-Fariñas M, Ungar B, Correa da Rosa J, Ewald DA, Rozenblit $\mathrm{M}$, Gonzalez J, et al. RNA sequencing atopic dermatitis transcriptome profiling provides insights into novel disease mechanisms with potential therapeutic implications. J Allergy Clin Immunol. (2015) 135:121827. doi: 10.1016/j.jaci.2015.03.003

89. Mattii M, Ayala F, Balato N, Filotico R, Lembo S, Schiattarella M, et al. The balance between pro- and anti-inflammatory cytokines is crucial in human allergic contact dermatitis pathogenesis: the role of IL-1 family members. Exp Dermatol. (2013) 22:813-9. doi: 10.1111/exd.12272

90. Zebrowska A, Wozniacka A, Juczynska K, Ociepa K, Waszczykowska E, Szymczak I, et al. Correlation between IL36 $\alpha$ and IL17 and activity of the disease in selected autoimmune blistering diseases. Mediators Inflamm. (2017) 2017:8980534. doi: 10.1155/2017/8980534

91. Nast A, Boehncke W-H, Mrowietz U, Ockenfels H-M, Philipp S, Reich K, et al. S3 - Guidelines on the treatment of psoriasis vulgaris (English version). update. J Dtsch Dermatol Ges. (2012) 10(Suppl. 2):S195. doi: 10.1111/j.1610-0387.2012.07919.x

92. Germán B, Wei R, Hener P, Martins C, Ye T, Gottwick C, et al. Disrupting the IL-36 and IL-23/IL-17 loop underlies the efficacy of calcipotriol and corticosteroid therapy for psoriasis. JCI Insight. (2019) 4:123390. doi: $10.1172 /$ jci.insight. 123390

93. Sand FL, Thomsen SF. Off-label use of TNF-alpha inhibitors in a dermatological university department: retrospective evaluation of 118 patients. Dermatol Ther. (2015) 28:158-65. doi: 10.1111/dth.12222

94. Tsai Y-C, Tsai T-F. Anti-interleukin and interleukin therapies for psoriasis: current evidence and clinical usefulness. Ther Adv Musculoskelet Dis. (2017) 9:277-94. doi: 10.1177/1759720X17735756
95. Viguier M, Guigue P, Pagès C, Smahi A, Bachelez H. Successful treatment of generalized pustular psoriasis with the interleukin-1-receptor antagonist Anakinra: lack of correlation with IL1RN mutations. Ann Intern Med. (2010) 153:66-7. doi: 10.7326/0003-4819-153-1-20100706000030

96. Rossi-Semerano L, Piram M, Chiaverini C, Ricaud D de, Smahi A, KonéPaut I. First clinical description of an infant with interleukin-36-receptor antagonist deficiency successfully treated with anakinra. Pediatrics. (2013) 132:e1043-7. doi: 10.1542/peds.2012-3935

97. Hüffmeier U, Wätzold M, Mohr J, Schön MP, Mössner R. Successful therapy with anakinra in a patient with generalized pustular psoriasis carrying IL36RN mutations. Br J Dermatol. (2014) 170:202-4. doi: 10.1111/bjd. 12548

98. Skendros P, Papagoras C, Lefaki I, Giatromanolaki A, Kotsianidis I, Speletas M, et al. Successful response in a case of severe pustular psoriasis after interleukin-1 $\beta$ inhibition. Br J Dermatol. (2017) 176:2125. doi: 10.1111/bjd.14685

99. Tauber M, Viguier M, Le Gall C, Smahi A, Bachelez H. Is it relevant to use an interleukin-1-inhibiting strategy for the treatment of patients with deficiency of interleukin-36 receptor antagonist? Br J Dermatol. (2014) 170:1198-9. doi: 10.1111/bjd.12805

100. Mahil SK, Catapano M, Di Meglio P, Dand N, Ahlfors H, Carr IM, et al. An analysis of IL-36 signature genes and individuals with IL1RL2 knockout mutations validates IL-36 as a psoriasis therapeutic target. Sci Transl Med. (2017) 9:eaan2514. doi: 10.1126/scitranslmed.aan2514

101. Ganesan R, Raymond EL, Mennerich D, Woska JR, Caviness G, Grimaldi $\mathrm{C}$, et al. Generation and functional characterization of anti-human and anti-mouse IL-36R antagonist monoclonal antibodies. MAbs. (2017) 9:114354. doi: 10.1080/19420862.2017.1353853

102. Sullivan GP, Henry CM, Clancy DM, Mametnabiev T, Belotcerkovskaya E, Davidovich P, et al. Suppressing IL-36-driven inflammation using peptide pseudosubstrates for neutrophil proteases. Cell Death Dis. (2018) 9:378. doi: 10.1038/s41419-018-0385-4

Conflict of Interest Statement: The authors declare that the research was conducted in the absence of any commercial or financial relationships that could be construed as a potential conflict of interest.

Copyright (c) 2019 Buhl and Wenzel. This is an open-access article distributed under the terms of the Creative Commons Attribution License (CC BY). The use, distribution or reproduction in other forums is permitted, provided the original author(s) and the copyright owner(s) are credited and that the original publication in this journal is cited, in accordance with accepted academic practice. No use, distribution or reproduction is permitted which does not comply with these terms. 